\title{
Progress on Plant-Level Modeling and Simulation of Used Nuclear Fuel Dissolution: Startup Condition with Quasi-Developed Flow and Varying Acid Concentration*
}

\author{
Valmor F. de Almeida \\ OAK Ridge National Laboratory \\ OAK RIDGE, TN 37831-6181, USA \\ Letter Report ORNL/LTR-2013/437
}

Approved for public release. Distribution is unlimited

The submitted manuscript has been authored by a contractor of the U.S. Government under the contract No. DE-AC05-00OR22725. Accordingly, the U.S. Government retains a nonexclusive, royalty-free license to publish or reproduce the published form of this contribution, or allow other to do so, for U.S. Government purposes.

20 September 2013

*Also available by request to dealmeidav@ornl. gov. 


\begin{abstract}
An update to a previous report is presented here describing the startup condition of a continuous dissolver. The need for a careful implementation of a startup condition is twofold. First, by varing the used fuel composition and various other parameters of the model, it becomes difficult to solve the governing equations accurately or to obtain a converged solution for an arbitrary initial condition. This is evident when coupling the dissolver module with a third-party user simulator. The second impetus for improving the modeling of the startup process is that an improved realism is obtained and the model is more complete and useful for accounting material balances rigorously.

The aforementioned previous report on this dissolver module is a required reading for the understanding of this update.
\end{abstract}




\section{Contents}

List of figures

List of tables $\quad$ iii

$1 \quad$ Startup with quasi-developed flow and varying acid concentration 1

1.1 Mass balance ..................... . . . . . 1

1.2 Constitutive restrictions . . . . . . . . . . . . . . . . . . . 2

1.2 .1 Volume constraints . . . . . . . . . . . . . . . . . 2

1.2 .2 Species partial molar volume . . . . . . . . . . . . . . . . . . 2

1.2 .3 Volumetric flow capacity function . . . . . . . . . . . . . . . . 3

1.3 Mathematical problem . . . . . . . . . . . . . . . . . 4

\begin{tabular}{|lll}
2 & Data needed and provided & 5
\end{tabular}

$\begin{array}{lll}3 & \text { Solution method and results } & 7\end{array}$

$3.1 \quad$ Breeder reactor fuel at $0.5 \mathrm{t} \mathrm{d}^{-1}$ dissolution capacity . . . . . . . . . . 7

3.1.1 Computed product stream (first compartment) characteristics 8

3.1.2 Computed compartment results . . . . . . . . . . . 10

3.2 Breeder reactor fuel at $1 \mathrm{td}^{-1}$ dissolution capacity . . . . . . . . . . . 11

3.2 .1 Computed product stream characteristics . . . . . . . . . . . . 12

3.2.2 Computed compartment results . . . . . . . . . . . . . . 14

$3.3 \quad$ LWR reactor fuel at $1.7 \mathrm{t} \mathrm{d}^{-1}$ dissolution capacity . . . . . . . . . . . 15

3.3 .1 Computed product stream characteristics . . . . . . . . . . . 17

3.3.2 Computed compartment results . . . . . . . . . . . . . . . . 19

$\begin{array}{llr}4 \text { Comments and future work } & 20\end{array}$

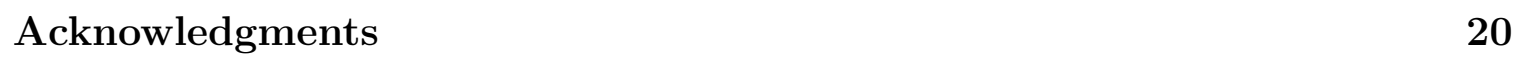

\begin{tabular}{lr}
\hline References & 20
\end{tabular}

\section{List of Figures}

3.1 Input concentration of $\mathrm{HNO}_{3}$ in the acid feed compartment $(k=9)$ $\begin{array}{ll}\text { with an imposed } 10 \% \text { random variation around the mean } 8.9 \mathrm{~mol} \mathrm{dm}^{-3} & 7\end{array}$

3.2 Computed volumetric flow rate of the product stream and corresponding mass density. Capacity of $0.5 \mathrm{td}^{-1} \ldots \ldots$. . . . . . . . . . 8

3.3 Startup for the volume of liquid in the first compartment and corresponding acid concentration. Capacity of $0.5 \mathrm{t} \mathrm{d}^{-1}$. . . . . . . . . . . 9 
3.4 Nitric acid molarity for each compartment of the dissolver. Capacity of $0.5 \mathrm{td}^{-1} \ldots \ldots \ldots \ldots \ldots \ldots \ldots$

3.5 Input concentration of $\mathrm{HNO}_{3}$ in the acid feed compartment $(k=9)$ \begin{tabular}{ll|l} 
with an imposed $10 \%$ random variation around the mean $10.4 \mathrm{~mol} \mathrm{dm}^{-3}$ & 11
\end{tabular}

3.6 Computed volumetric flow rate of the product stream and corresponding mass density. Capacity of $1 \mathrm{t} \mathrm{d}^{-1} \ldots \ldots . \ldots . \ldots 12$

3.7 Startup for the volume of liquid in the first compartment and corresponding acid concentration. Capacity of $1 \mathrm{td}^{-1} \ldots \ldots$. . . . . . . 13

3.8 Nitric acid molarity for each compartment of the dissolver. Capacity of $1 \mathrm{td}^{-1} \ldots \ldots \ldots \ldots \ldots \ldots \ldots$

3.9 Input concentration of $\mathrm{HNO}_{3}$ in the acid feed compartment $(k=9)$ \begin{tabular}{ll|l} 
with an imposed $10 \%$ random variation around the mean $9.7 \mathrm{~mol} \mathrm{dm}^{-3}$ & 16
\end{tabular}

3.10 Computed volumetric flow rate of the product stream and correspond-

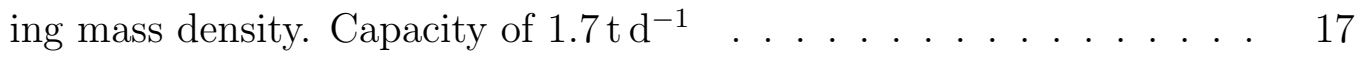

3.11 Startup for the volume of liquid in the first compartment and corresponding acid concentration. Capacity of $1.7 \mathrm{t} \mathrm{d}^{-1} \ldots \ldots$. . . . . . 18

3.12 Nitric acid molarity for each compartment of the dissolver. Capacity

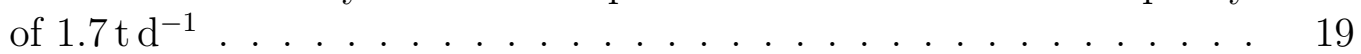

\section{List of Tables}

$2.1 \quad$ Data for breeder reactor used fuel dissolution at $0.5 \mathrm{t} \mathrm{d}^{-1}$ capacity . . 5

2.2 Data for breeder reactor used fuel dissolution at $1 \mathrm{t} \mathrm{d}^{-1}$ capacity . . . 6

2.3 Data for LWR reactor used fuel dissolution at $1.7 \mathrm{t} \mathrm{d}^{-1}$ capacity . . . 6 


\section{Startup with quasi-developed flow and varying acid concentration}

The fluid flow startup of the rotary dissolver takes place in two steps. First, an empty rotary dissolver receives water (either pure or slightly acidic) at the upper end which creates a pool in the discharge compartment as the flow level reaches the corresponding partition slot. As the water overflows the slots, the next compartment downstream begins receiving water and, similarly, a pool is formed at the bottom of the drum. This cascade startup continues until all compartments have a pool of liquid, and there exists a steady-state, fully developed flow of water through the rotary dissolver (fig. 3.1, de Almeida, 2012).

In the second startup step a nitric acid feed is added to the penultimate compartment. Mixing takes place by convection of the flowing water and by rotation of the drum. The product stream at the feed compartment is monitored for the acid concentration until it reaches a stationary value. This defines the end of the flow startup procedure.

In the first step the liquid flow rate and the volume of liquid in each compartment change with time until steady state. Each compartment starts dry, therefore the transient is due to the rising of the liquid level up to the slot height, and the formation of the overflow head above the slot. In the second step, the concentration of nitric acid changes in each compartment (except at the solid discharge end) and so does the liquid volume and the flow rate in view of the added acid stream and the non-ideality of the solution.

Only the second step is considered in this report. Denote the second step time interval as

$$
I_{2}:=\left\{t \in \mathbb{P} \mid 0 \leq t \leq T_{2}\right\}
$$

The governing equations for the startup process need to be integrated in $I_{2}$.

\subsection{Mass balance}

A vertex-wise mass balance for the liquid phase on the $k$ th vertex with material flow from its neighbors results in

$$
\begin{aligned}
d_{t}\left(\rho_{a}^{(k)} V^{(k)}\right)=\sum_{j \neq k} \rho_{a}^{(k)} f^{(\overrightarrow{k, j})}+\mathscr{M}_{a}^{(k)} \quad \forall \quad k=1, \ldots, N_{\mathrm{v}}, \\
\\
\text { and } \quad a=1, \ldots, \mathcal{A}^{(k)} .
\end{aligned}
$$

Oak Ridge National Laboratory Report ORNL/TM-2012/375 pp. 1-21 
For the particular linear network of vertices used in the current model, the summation in (1.1) can be simply expressed as

$$
\sum_{j \neq k} \rho_{a}^{(k)} f^{(\overrightarrow{k, j})}=:-\rho_{a}^{(k)} f^{(k)}+\rho_{a}^{(k+1)} f^{(k+1)}
$$

Where $f^{(k)} \geq 0$ is the volumetric flow rate leaving the $k$ th vertex stage and $f^{(k+1)} \geq 0$ is the corresponding flow entering the stage. Here the number of vertices is $N_{\mathrm{v}}=10$, backmixing and frontmixing terms have been neglected (de Almeida, 2011, (5.3)), the number of species in the liquid phase is $\mathcal{A}^{(k)}=2$, with mass concentration for each specie denoted as $\rho_{\mathrm{H}_{2} \mathrm{O}}^{(k)}$ and $\rho_{\mathrm{HNO}_{3}}^{(k)}$, respectively, for every vertex.

The source/sink terms $\mathscr{M}_{a}^{(k)}=0 \forall k \neq 9$ reduce to only one nonzero term that accounts for the injection of the acid stream in the penultimate compartment, $\mathscr{M}_{a}^{(9)}$, which must account for the water and nitric acid sources.

\subsection{Constitutive restrictions}

Since (1.1) has not been specialized for a particular liquid mixture, it is nonsolvable. This is resolved by proposing constitutive restrictions of volume constraint type to close the mathematical model.

\subsubsection{Volume constraints}

The job at hand is to quantify volume changes in the liquid mixture (the gas phase has been neglected in this development). There are two components for the change of liquid volume in a network $k$-stage vertex, $V^{(k)}$, namely, change by creation of species, and change by convection of material to and from the stage in view of the holdup capacity inherent in each digestor compartment. The former is a change of chemical nature, the latter, a change of mechanical fluid flow. These considerations will generate the remaining 2 constitutive equations needed to close the model.

\subsubsection{Species partial molar volume}

As chemical species are formed or introduced into a stream, a change in volume of the liquid phase results. This molecular phenomenon is instantaneous relative to the time scale of the dissolution of a pellet and the revolution time of the digestor. Therefore, a thermodynamical equilibrium assumption for this particular aspect is acceptable at this point. The volume of the liquid phase in the $k$ th network vertex is then a 
function of the molar fraction, $x_{a}$, and partial molar volumes of the solutes

$$
V^{(k)}(t)=\sum_{a=1}^{2} x_{a}^{(k)}(t) \bar{V}_{a} \quad \text { where } \quad \bar{V}_{a}:=\left(\partial_{x_{a}} V\right)_{P, T, x_{b} \neq a} .
$$

The partial molar volumes of all species, $\left(\partial_{x_{a}} V\right)_{P, T, x_{b} \neq a}$ is a thermodynamic property at constant temperature $\mathrm{T}$ and pressure $\mathrm{P}$ obtained either from tabulated experimental data or an off-line thermodynamic simulation, say via equilibrium molecular dynamics. Another form of expressing the previous constitutive restriction is in the form of a mass density constraint for the liquid mixture

$$
\rho^{(k)}(t):=\sum_{a=1}^{2} \rho_{a}^{(k)}=R\left(T, P, x_{a=1,2}\right)
$$

which is the needed response function form (de Almeida, 2012). This constitutive equation augments the basic set by enforcing a particular material behavior. In particular, it accounts for non-ideality of the liquid mixture from a thermodynamics stand point. A restricted empirical form of (1.2) was used from (Lewis, 1984).

\subsubsection{Volumetric flow capacity function}

A second mechanism of volume variation in the liquid phase is the variable flow capacity of each digester compartment. A direct flow balance for each $k$-stage, ignoring the effects of hydrodynamic backmixing/frontmixing, leads to

$$
d_{t} V^{(k)}=-C\left(V^{(k)}, \Omega\right)+f^{(k+1)}+\mathscr{F}^{(k)}
$$

where the capacity function, $C:\left(V^{(k)}, \Omega\right) \in \mathbb{P} \times \mathbb{P} \rightarrow \mathbb{P}$, provides the volumetric flow rate of the exiting liquid phase as a function of the existing volume of the liquid, and the rotation rate of the dissolver. An empirical power-law function was used in this work which relates flow rate to liquid phase volume (Lewis and Weber, 1980)

$$
C\left(V^{(k)}, \Omega\right):=\left\{\begin{array}{cl}
\left(\frac{V^{(k)}-V_{0}}{G}\right)^{p} & \text { if } V^{(k)}-V_{0}>0 \\
0 & \text { otherwise. }
\end{array}\right.
$$

The volumetric flow rate source/sink $\mathscr{F}^{(k)}$ accounts for any injection or withdraw of liquid in the $k$ th stage. The only place this source is used in the current dissolver prototype is in the penultimate compartment $(k=9)$ where the acid feed is introduced (de Almeida, 2012). 


\subsection{Mathematical problem}

A presentation of the governing equations in the form of a mathematical problem is in order to help define a solution strategy. Upon collecting the equations previously stated, the mathematical problem can be stated as follows: find the time-dependent functions $(\cdot): t \in I_{2} \rightarrow \mathbb{R}$ during the second startup step

$$
\rho_{a}^{(k)}, V^{(k)}, f^{(k)}, \text { for } \forall a=1,2, k=1, \ldots, 10,
$$

satisfying the basic network equations

$$
d_{t}\left(\rho_{a}^{(k)} V^{(k)}\right)=-\rho_{a}^{(k)} f^{(k)}+\rho_{a}^{(k+1)} f^{(k+1)}+\mathscr{M}_{a}^{(k)},
$$

and the constitutive equations

$$
\begin{aligned}
d_{t} V^{(k)} & =-C\left(V^{(k)}, \Omega\right)+f^{(k+1)}+\mathscr{F}^{(k)}, \text { and } \\
\sum_{a=1}^{2} \rho_{a}^{(k)} & =R\left(T, P, x_{a=1,2}\right),
\end{aligned}
$$

using the sources $\mathscr{M}_{a}^{(k)}=0 \forall k \neq 9$, the constitutive thermodynamics, and flow capacity functions, respectively $R(\cdot)$, and $C(\cdot)$, and the volumetric flow rate sources $\mathscr{F}^{(k)}=0 \forall k \neq 9$. The nonzero mass balance sources are: $\mathscr{M}_{\mathrm{H}_{2} \mathrm{O}}^{(9)}(t):=\mathscr{F}^{(9)}(t) \mathscr{C}_{\mathrm{H}_{2} \mathrm{O}}^{(9)}(t) M_{\mathrm{H}_{2} \mathrm{O}}$ and $\mathscr{M}_{\mathrm{HNO}_{3}}^{(9)}(t):=\mathscr{F}(9)(t) \mathscr{C}_{\mathrm{HNO}_{3}}^{(9)}(t) M_{\mathrm{HNO}_{3}}$.

Equations (1.5a) $-(1.5 \mathrm{~d})$ require initial conditions at $t=0$, i.e.,

$$
\begin{aligned}
\rho_{a}^{(k)}(0)={ }_{0} \rho_{a}^{(k)}, V^{(k)}(0) & ={ }_{0} V^{(k)}, f^{(k)}(0)={ }_{0} f^{(k)} \\
& \forall a=1,2, \quad \forall k=1, \ldots, 10 \\
& \quad \text { and } \quad \rho_{a}^{(11)}(0)={ }_{0} \rho_{a}^{(11)}, f^{(11)}(0)={ }_{0} f^{(11)}
\end{aligned}
$$

The quantities on the right side of the equations (1.6) denote the data needed at the startup of the dissolver operation in this model. Note also that the data $\rho_{a=1,2}^{(11)}(0)=$ ${ }_{0} \rho_{a=1,2}^{(11)}$ and $f^{(11)}(0)={ }_{0} f^{(11)}$ represent the external flow into the rinse/discharge compartment; these can be a function of time. An additional feature of the dissolver initial condition is that the acid feed enters in the penultimate compartment. Therefore the source $\mathscr{M}_{a=1,2}^{(9)}$ must include the addition of $\mathrm{H}_{2} \mathrm{O}$ and $\mathrm{HNO}_{3}$ from this feed stream with volumetric flow rate denoted $\mathscr{F}^{(9)}$; these quantities can all be time dependent (e.g. fig. 3.1).

Provided a solution to the mathematical problem $1.5 \mathrm{a}-1.6$ exists, the functions (1.5) are determined in the interval $I_{2}$. 


\section{Data needed and provided}

Parameters in tables 2.1, and 2.2 were used for testing the solution method. Three parametric scenarios were explored using the same dissolver geometry (de Almeida, 2012). First, a $0.5 \mathrm{t} \mathrm{d}^{-1}$ capacity for dissolving breeder reactor fuel was tested. Second, the same fuel but a larger capacity, $1 \mathrm{td}^{-1}$, was used. Last, a $1.7 \mathrm{td}^{-1}$ capacity for used, light water reactor (LWR) fuel was designed for collaboration with a safeguards application (Cipiti and McDaniel, 2011; Cipiti et al., 2009).

Table 2.1: Data for breeder reactor used fuel dissolution at $0.5 \mathrm{t} \mathrm{d}^{-1}$ capacity.

\begin{tabular}{|c|c|c|}
\hline Quantity & Value & Description \\
\hline$f^{(11)}$ & $0.4 \mathrm{~L} / \mathrm{min}$ & $\begin{array}{l}\text { Volumetric liquid flow rate of the rinse } \\
\text { stream to the discharge (rinse) compart- } \\
\text { ment }\end{array}$ \\
\hline$c_{\mathrm{HNO}_{3}}^{(11)}$ & $0 \mathrm{M}$ & $\begin{array}{l}\text { Nitric acid molarity in rinse feed stream in } \\
\text { the last compartment }\end{array}$ \\
\hline$\rho_{\mathrm{H}_{2} \mathrm{O}}^{(11)}$ & $971 \mathrm{~g} \mathrm{~L}^{-1}$ & $\begin{array}{l}\text { Water mass concentration in the feed } \\
\text { stream to the discharge compartment }\end{array}$ \\
\hline$V_{0}$ & $10.3 \mathrm{~L}$ & $\begin{array}{l}\text { Yield volume parameter in the flow capac- } \\
\text { ity function }\end{array}$ \\
\hline$p$ & 2.7 & $\begin{array}{l}\text { Power-law exponent in the flow capacity } \\
\text { function }\end{array}$ \\
\hline G & $0.201941 \mathrm{~L}$ & Volume factor in the flow capacity function \\
\hline $\mathscr{F}^{(9)}$ & $1.5 \mathrm{~L} / \min$ & $\begin{array}{l}\text { Volumetric liquid flow rate of the feed } \\
\text { stream in the penultimate compartment } \\
(k=9)\end{array}$ \\
\hline $\mathscr{C}_{\mathrm{HNO}_{3}}^{(9)}(0)$ & $8.9 \mathrm{M}$ & $\begin{array}{l}\text { Initial nitric acid molarity in the acid feed } \\
\text { stream in the penultimate compartment }\end{array}$ \\
\hline $\mathscr{C}_{\mathrm{H}_{2} \mathrm{O}}^{(9)}(0)$ & $37.3 \mathrm{M}$ & $\begin{array}{l}\text { Initial water molarity in the acid feed } \\
\text { stream in the penultimate compartment }\end{array}$ \\
\hline
\end{tabular}


Table 2.2: Data for breeder reactor used fuel dissolution at $1 \mathrm{t} \mathrm{d}^{-1}$ capacity. Other quantities as in table 2.1.

\begin{tabular}{|c|c|l|}
\hline Quantity & Value & Description \\
\hline \hline$f^{(11)}$ & $0.6 \mathrm{~L} / \mathrm{min}$ & $\begin{array}{l}\text { Volumetric liquid flow rate of the rinse } \\
\text { stream to the discharge (rinse) compart- } \\
\text { ment } \\
\text { Volumetric liquid flow rate of the feed } \\
\text { stream in the penultimate compartment } \\
(k=9)\end{array}$ \\
$\mathscr{F}^{(9)}$ & $2 \mathrm{~L} / \mathrm{min}$ & $\begin{array}{l}\text { Initial nitric acid molarity in the acid feed } \\
\text { stream in the penultimate compartment } \\
\text { Initial water molarity in the acid feed } \\
\text { stream in the penultimate compartment }\end{array}$ \\
$\mathscr{C}_{\mathrm{HNO}_{3}(0)}^{(9)}$ & $10.4 \mathrm{M}$ \\
$\mathscr{C}_{\mathrm{H}_{2} \mathrm{O}}^{(9)}(0)$ & $34.6 \mathrm{M}$ & \multicolumn{2}{c}{}
\end{tabular}

Table 2.3: Data for $L W R$ reactor used fuel dissolution at $1.7 \mathrm{t} \mathrm{d}^{-1}$ capacity. Other quantities as in tables 2.1 2.2.

\begin{tabular}{|c|c|c|}
\hline Quantity & Value & Description \\
\hline$f^{(11)}$ & $2 \mathrm{~L} / \min$ & $\begin{array}{l}\text { Volumetric liquid flow rate of the rinse } \\
\text { stream to the discharge (rinse) compart- } \\
\text { ment }\end{array}$ \\
\hline$V_{0}$ & $21 \mathrm{~L}$ & $\begin{array}{l}\text { Yield volume parameter in the flow capac- } \\
\text { ity function }\end{array}$ \\
\hline $\mathscr{F}^{(9)}$ & $3 \mathrm{~L} / \min$ & $\begin{array}{l}\text { Volumetric liquid flow rate of the feed } \\
\text { stream in the penultimate compartment } \\
(k=9)\end{array}$ \\
\hline $\mathscr{C}_{\mathrm{HNO}_{3}}^{(9)}(0)$ & $9.7 \mathrm{M}$ & $\begin{array}{l}\text { Initial nitric acid molarity in the acid feed } \\
\text { stream in the penultimate compartment }\end{array}$ \\
\hline $\mathscr{C}_{\mathrm{H}_{2} \mathrm{O}}^{(9)}(0)$ & $35.9 \mathrm{M}$ & $\begin{array}{l}\text { Initial water molarity in the acid feed } \\
\text { stream in the penultimate compartment }\end{array}$ \\
\hline
\end{tabular}

Oak Ridge National Laboratory Report ORNL/TM-2012/375 pp. 121 


\section{Solution method and results}

The problem (1.5) is an example of a system of differential algebraic equations (DAE) with index one. The solution method applied here has been discussed before (de Almeida, 2012). The next sections demonstrate tests for a startup of the rotary dissolver within a condition of quasi-developed flow and perturbed input acid concentration; solids are not present.

\subsection{Breeder reactor fuel at $0.5 \mathrm{t} \mathrm{d}^{-1}$ dissolution capacity}

Time variations in the results presented next are characterized by two scales. First, variations on the concentration of $\mathrm{HNO}_{3}$ in the feed stream. Second,variations of volumes due to the addition of fluid mass and non-ideality of the solution. Parameters for the present case are those presented in table 2.1. In this section results for the startup step when a quasi-developed flow is used with a varying input acid concentration are shown. The latter is obtained by a random variation of a maximum of $10 \%$; the mean acid concentration is reported in table $2.1\left(\mathscr{C}_{\mathrm{HNO}_{3}}^{(9)}(0)=8.9 \mathrm{M}\right)$.

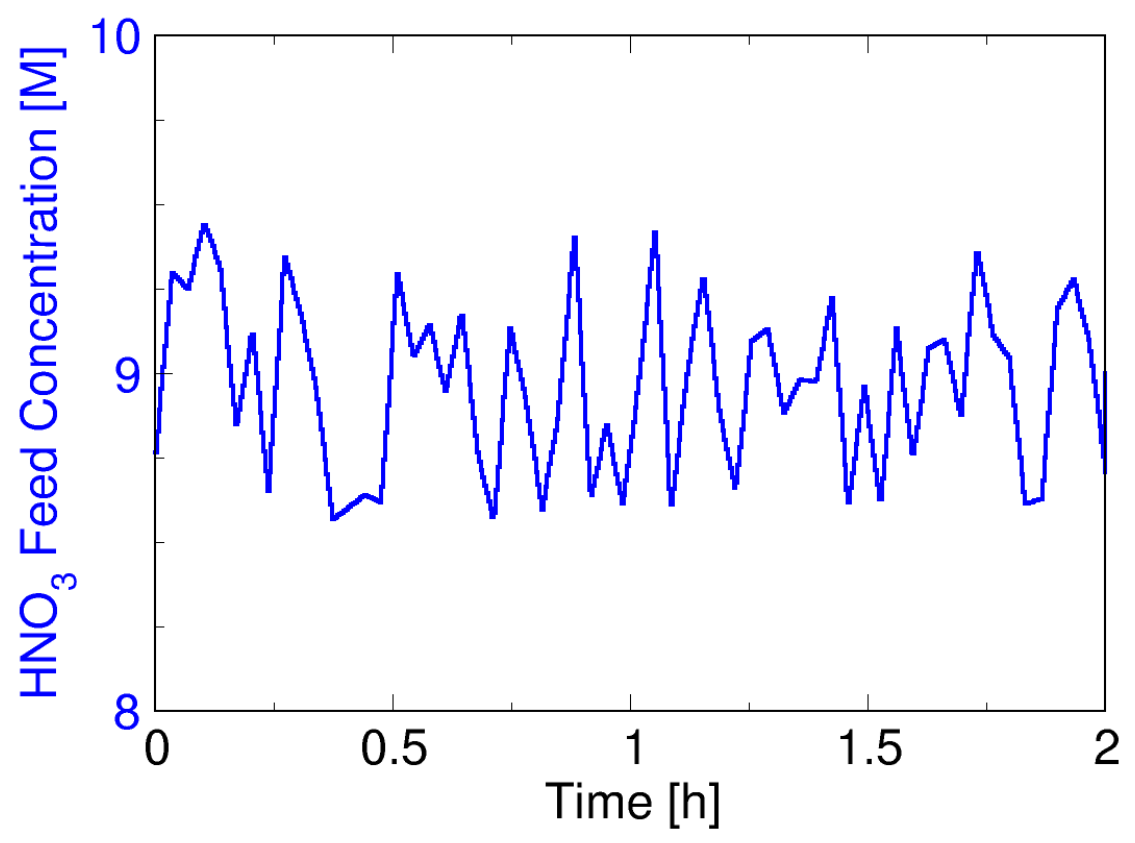

Fig. 3.1: Input concentration of $\mathrm{HNO}_{3}$ in the acid feed compartment $(k=9)$ with an imposed $10 \%$ random variation around the mean of $8.9 \mathrm{M}$. This is the graphical representation of the piecewise linear random function $\mathscr{C}_{\mathrm{HNO}_{3}}^{(9)}(t)$. 


\subsubsection{Computed product stream (first compartment) characteristics}

The product stream exits the first compartment of the dissolver and it provides the primary data for coupling the dissolution with downstream processes such as digestors, holding tanks, etc. Therefore various plots representing the time variation of the predicted results are presented in this section for the startup step when a quasi-developed flow is used with a varying input acid concentration.

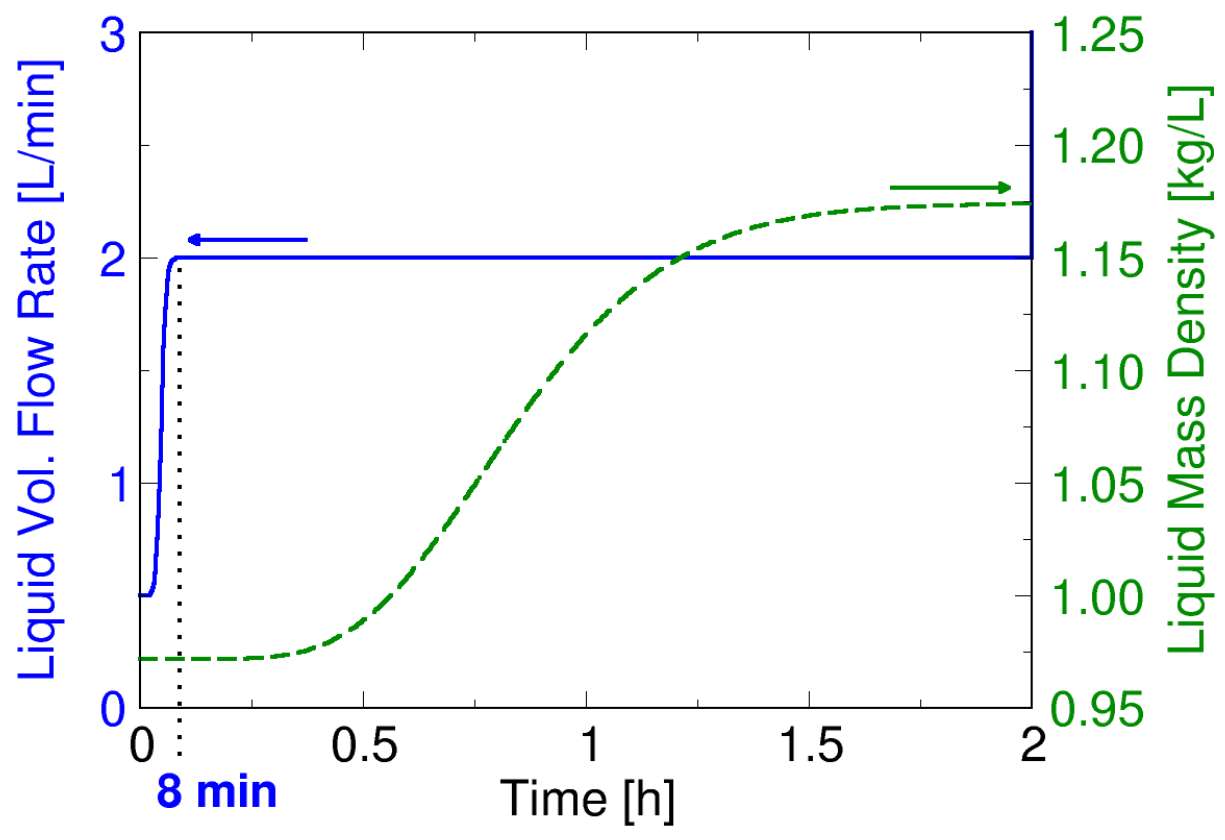

Fig. 3.2: Computed volumetric flow rate of the product stream and corresponding mass density. Capacity of $0.5 \mathrm{t} \mathrm{d}^{-1}$. 


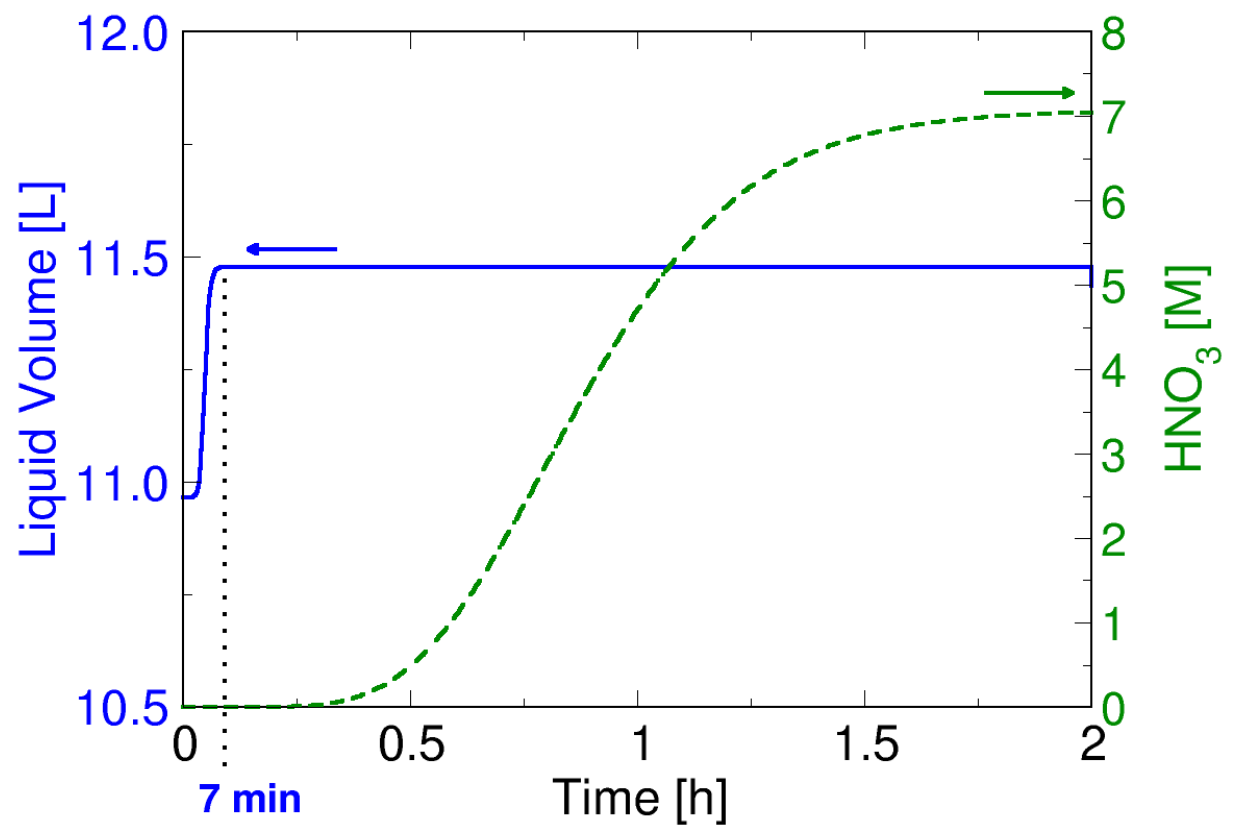

Fig. 3.3: Startup for the volume of liquid in the first compartment and corresponding acid concentration. Capacity of $0.5 \mathrm{t} \mathrm{d}^{-1}$. 


\subsubsection{Computed compartment results}

Results in this section show quantities computed on a compartment basis.

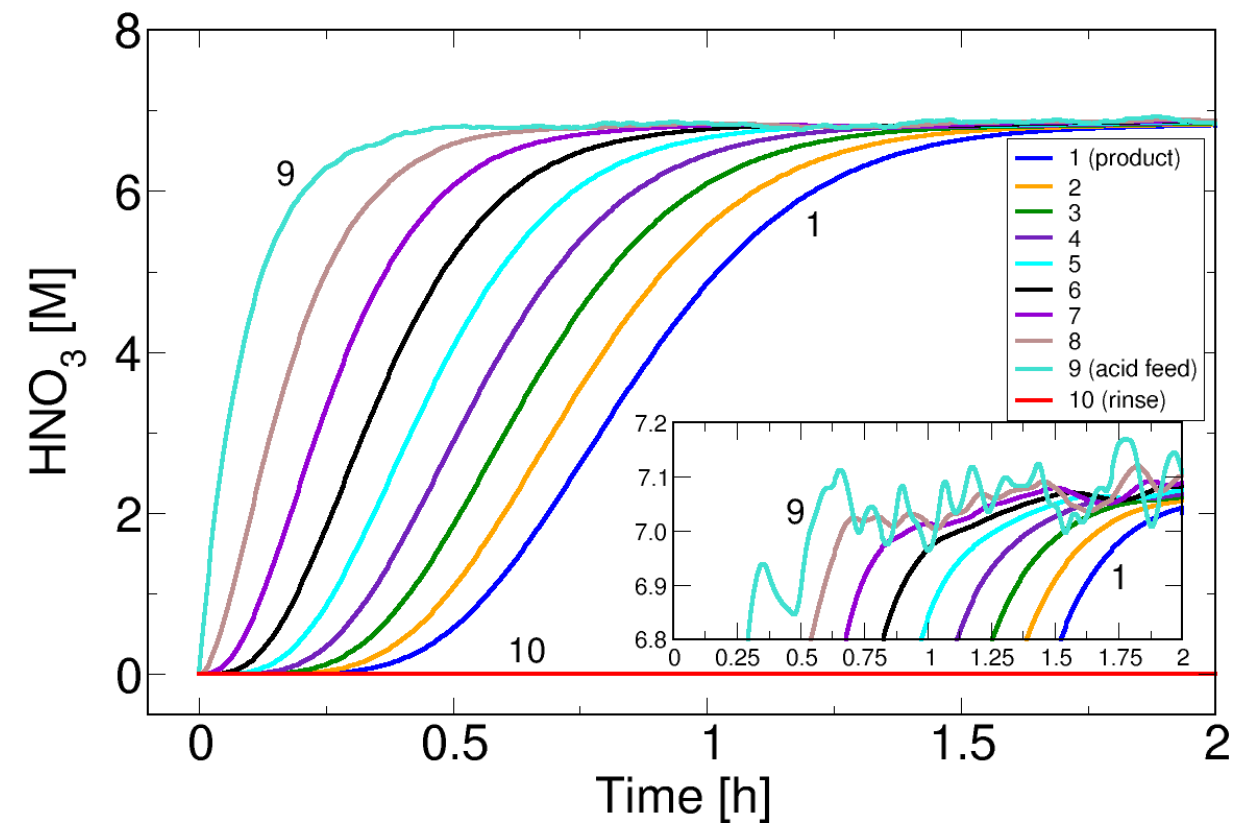

Fig. 3.4: Nitric acid molarity for each compartment of the dissolver. Capacity of $0.5 \mathrm{t} \mathrm{d}^{-1}$. The zoom-in graph shows how the perturbation of the concentration in the feed compartment decays in the downstream direction. 


\subsection{Breeder reactor fuel at $1 \mathrm{td}^{-1}$ dissolution capacity}

Results in this section utilize the same dissolver geometry as in the previous section but the operating parameters are modified to allow for a greater reprocessing capacity (table 2.2).

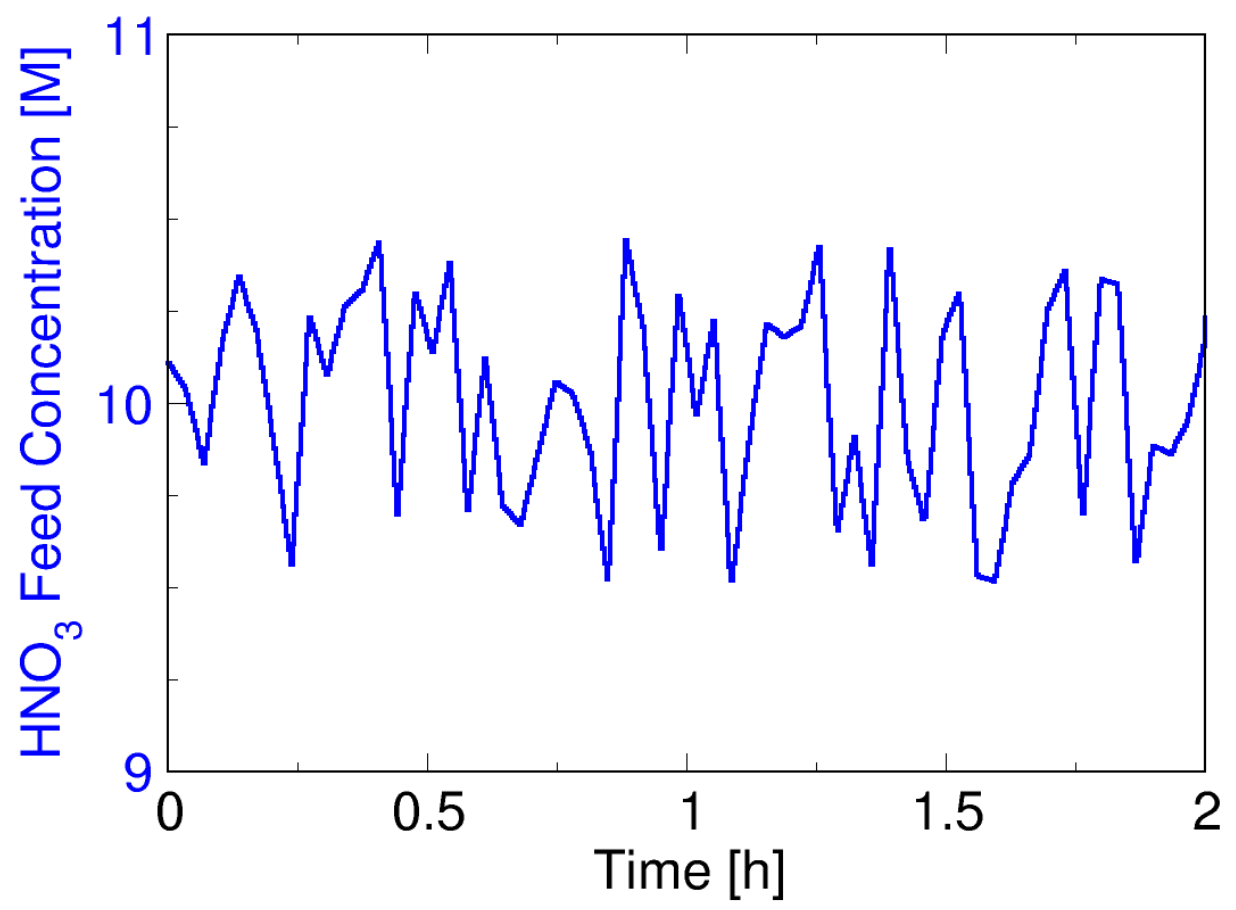

Fig. 3.5: Input concentration of $\mathrm{HNO}_{3}$ in the acid feed compartment $(k=9)$ with an imposed $10 \%$ random variation around the mean of $10.4 \mathrm{M}$. This is the graphical representation of the piecewise linear random function $\mathscr{C}_{\mathrm{HNO}_{3}}^{(9)}(t)$. 


\subsubsection{Computed product stream characteristics}

The product stream exits the first compartment of the dissolver and it provides the primary data for coupling the dissolution with downstream processes such as digestors, holding tanks, etc. Therefore various plots representing the the time variation of the predicted results are presented in this section for the scaled up dissolution capacity of $1 \mathrm{t} \mathrm{d}^{-1}$.

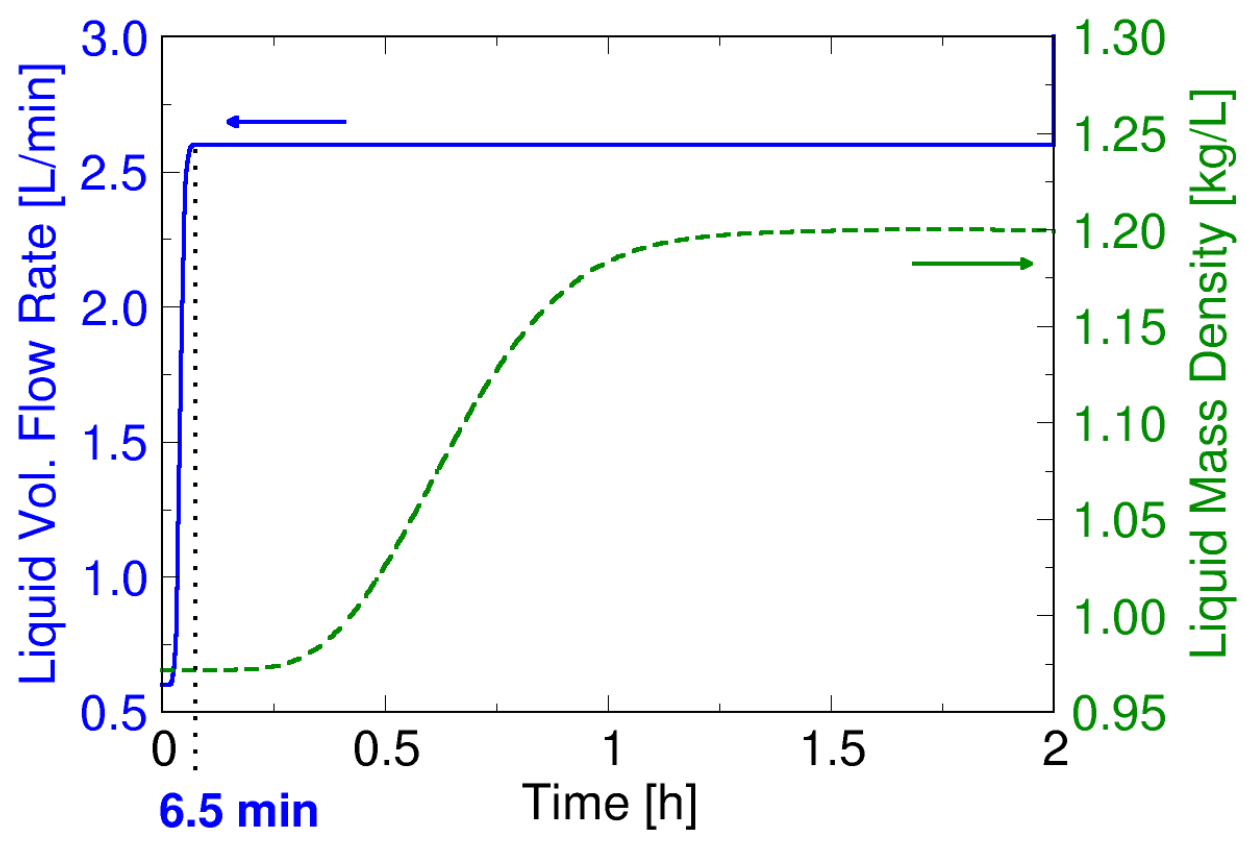

Fig. 3.6: Computed volumetric flow rate of the product stream and corresponding mass density. Capacity of $1 \mathrm{td}^{-1}$. 


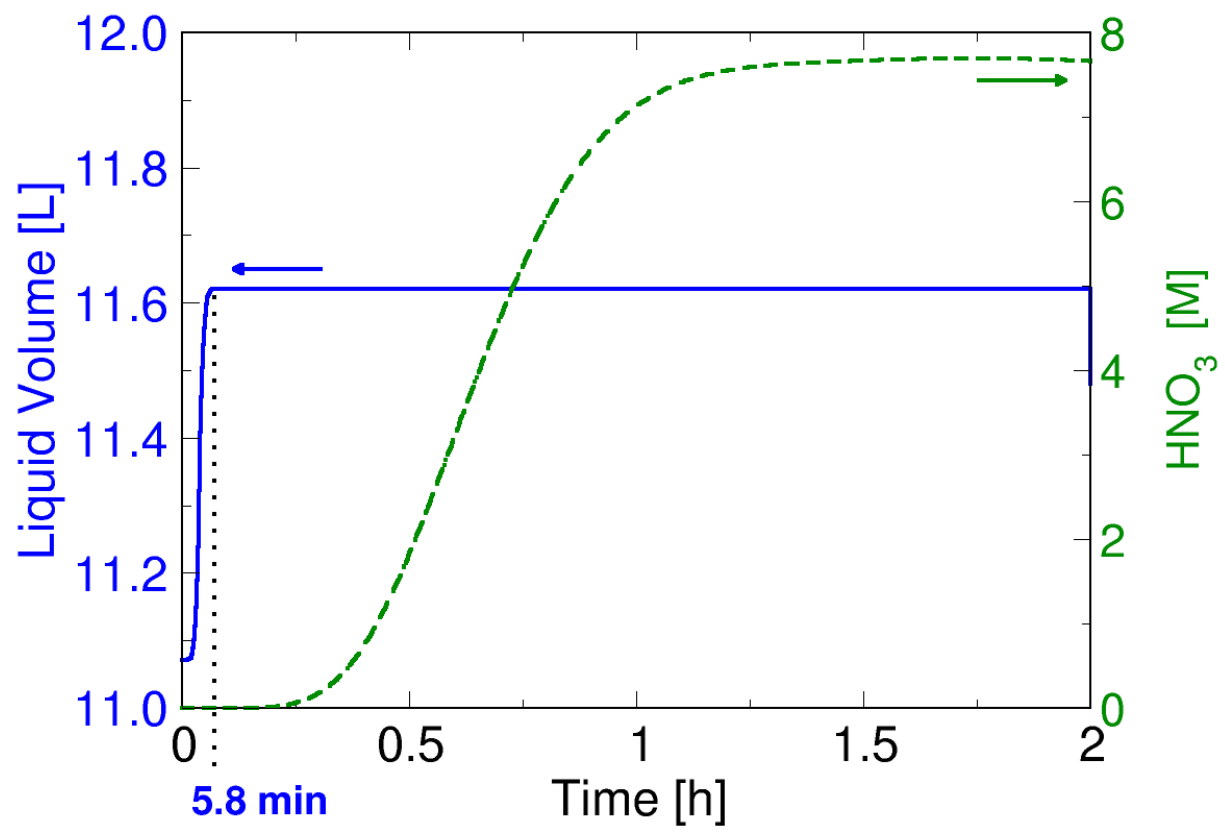

Fig. 3.7: Startup for the volume of liquid in the first compartment and corresponding acid concentration. Capacity of $1 \mathrm{td}^{-1}$. 


\subsubsection{Computed compartment results}

Results in this section show quantities computed on a compartment basis.

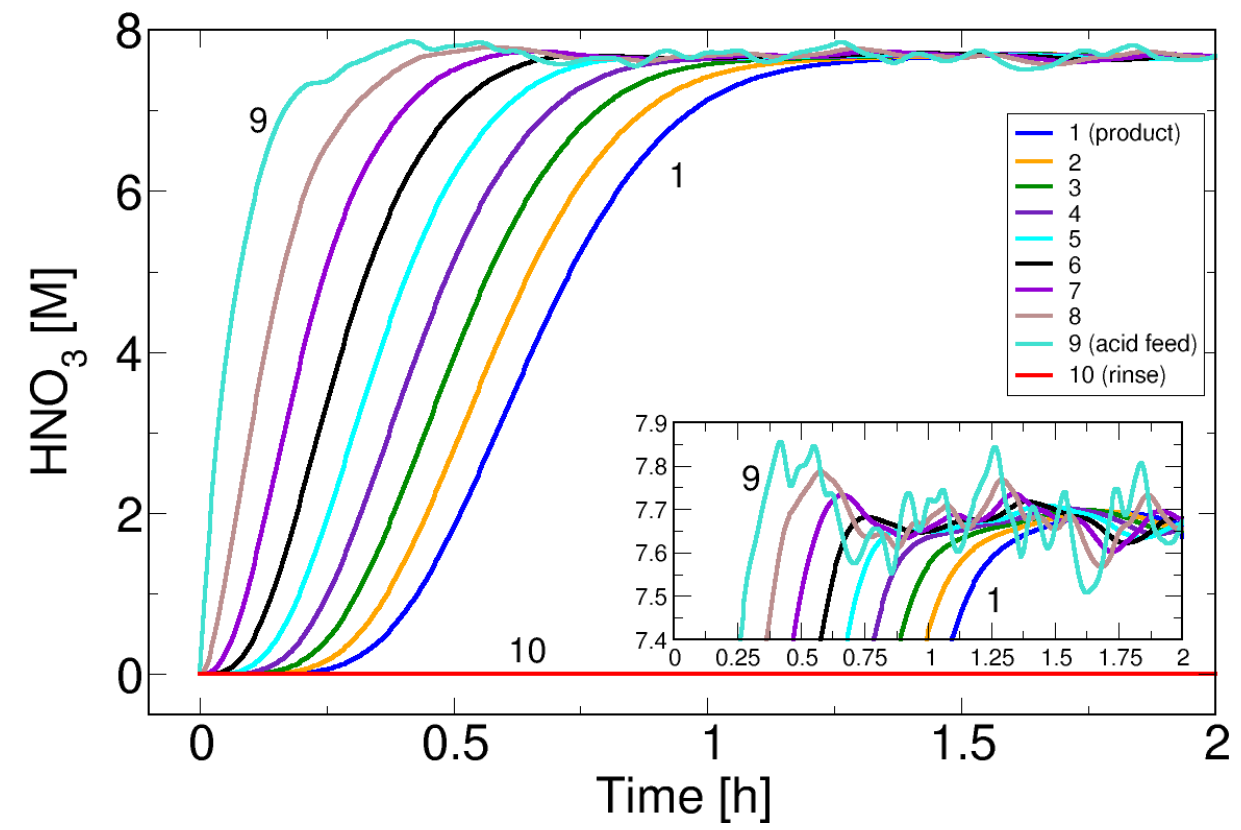

Fig. 3.8: Nitric acid molarity for each compartment of the dissolver. Capacity of $1 \mathrm{td}^{-1}$. The zoom-in graph shows how the perturbation of the concentration in the feed compartment decays in the downstream direction. 


\subsection{LWR reactor fuel at $1.7 \mathrm{t} \mathrm{d}^{-1}$ dissolution capacity}

In this test, a geometry scale-up is necessary. Here only a change in diameter of the rotary dissolver was attempted. In this case, the partition slots should be position such that a liquid depth corresponding to a $21 \mathrm{~L}$-pool is available in each compartment of the dissolver.

The results presented in this section were used to test the computer program provided to the Separations and Safeguards Performance Model (SSPM) code (Cipiti and McDaniel, 2011; Cipiti et al., 2009). The program was written in MATLAB language as a stand-alone module that can be invoked by the Simulink environment used in the SSPM application. There are still significant challenges to integrate modules into existing plant-level computational environments. The present application is an example of a model that may require continuous variation of inputs therefore making it difficult to couple, mathematically, with exterior models. The work done here follows a commonality design approach (de Almeida, 2011) to enable mathematical coupling. Work in progress for testing the coupling method with the SSPM is described by Cipiti and McDaniel (2011). Future work will focus in evaluating proper time evolution of the coupled systems. 


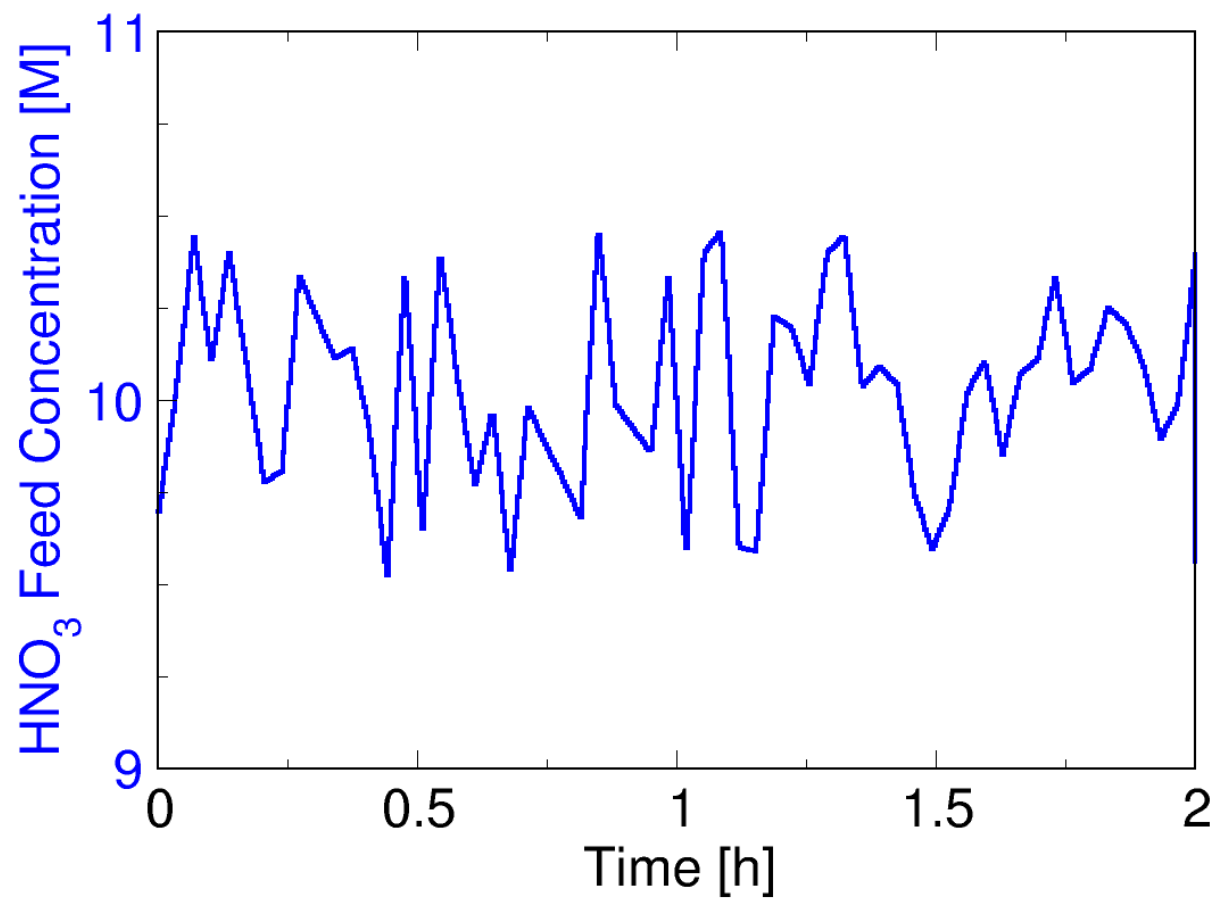

Fig. 3.9: Input concentration of $\mathrm{HNO}_{3}$ in the acid feed compartment ( $k=9$ ) with an imposed $10 \%$ random variation around the mean of $9.7 \mathrm{M}$. This is the graphical representation of the piecewise linear random function $\mathscr{C}_{\mathrm{HNO}_{3}}^{(9)}(t)$. 


\subsubsection{Computed product stream characteristics}

Here the primary output data provided to the SSPM application are shown in graphic form.

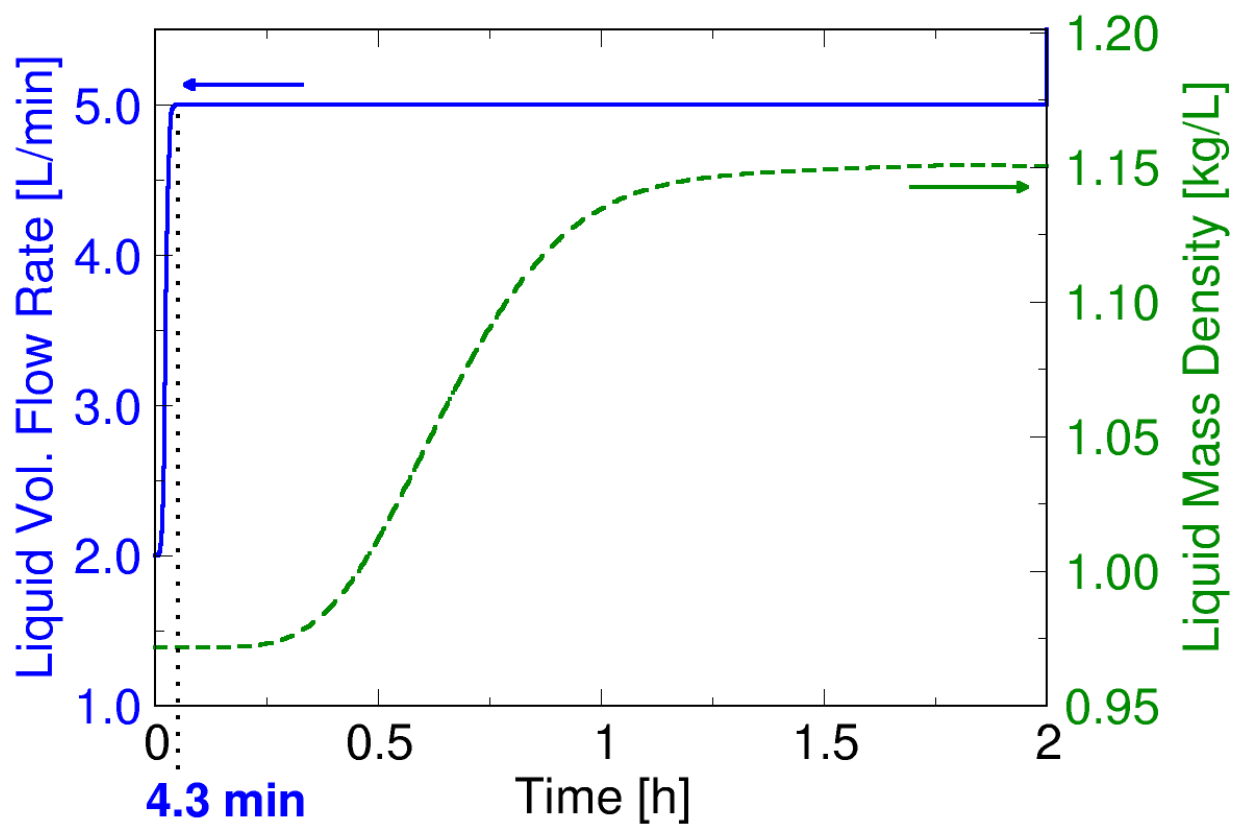

Fig. 3.10: Computed volumetric flow rate of the product stream and corresponding mass density. Capacity of $1.7 \mathrm{td}^{-1}$. 


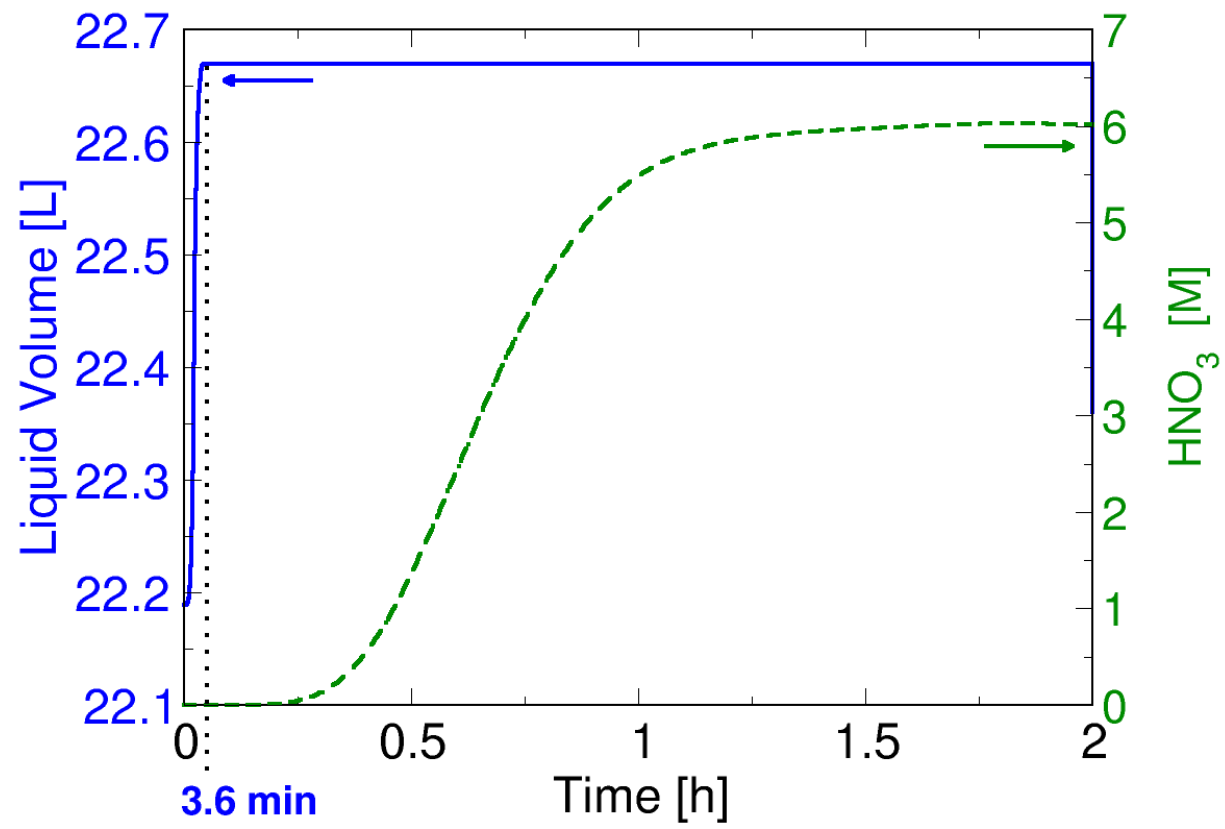

Fig. 3.11: Startup for the volume of liquid in the first compartment and corresponding acid concentration. Capacity of $1.7 \mathrm{t} \mathrm{d}^{-1}$. 


\subsubsection{Computed compartment results}

Results in this section show quantities computed on a compartment basis.

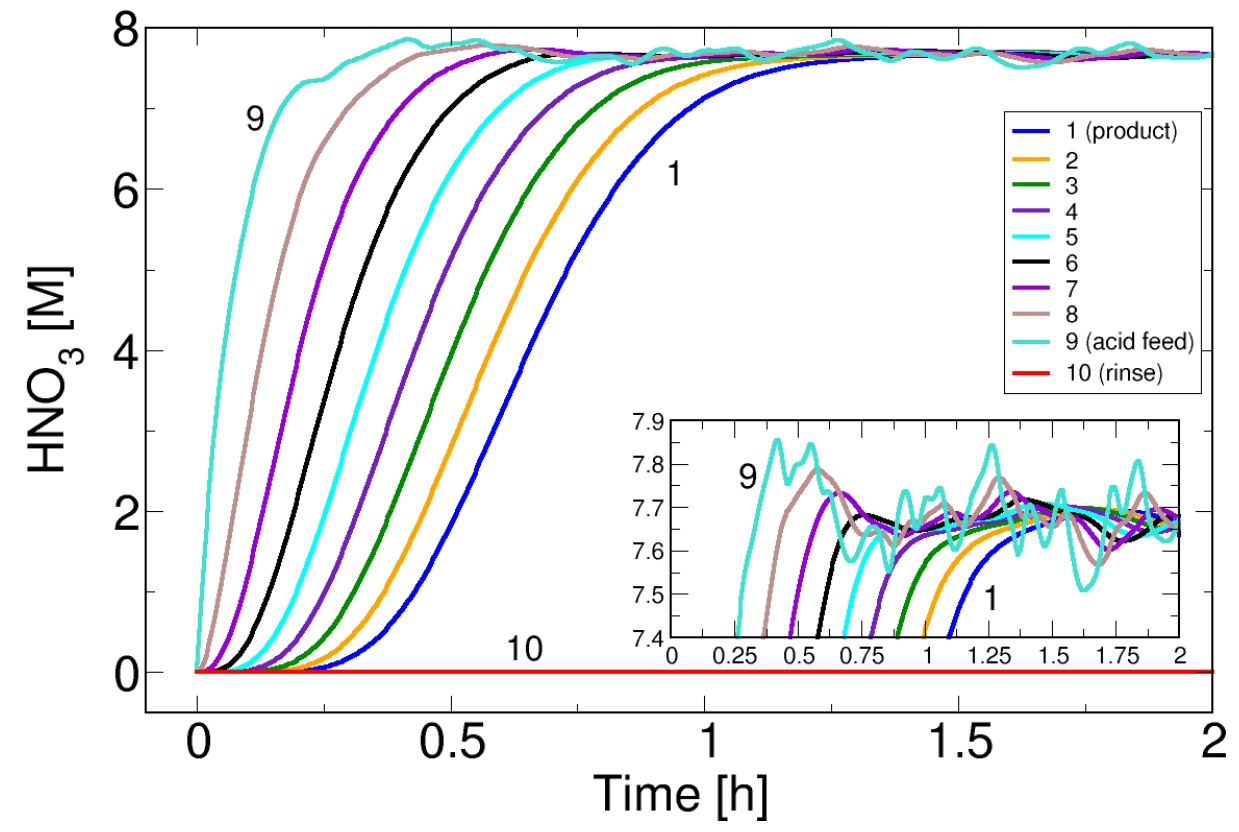

Fig. 3.12: Nitric acid molarity for each compartment of the dissolver. Capacity of $1.7 \mathrm{t} \mathrm{d}^{-1}$. The zoom-in graph shows how the perturbation of the concentration in the feed compartment decays in the downstream direction. 


\section{Comments and future work}

This continued development implemented and tested a startup condition for the dissolver module described earlier (de Almeida, 2012). The module has been tested by coupling with the SSPM code wherein the resulting application performed correctly and robustly.

Future work on this topic will implement the startup step with a dry rotary drum.

\section{Acknowledgments}

This work was sponsored by the U.S. Department of Energy through the Office of Nuclear Energy and its Separations and Waste Forms technical group in the Fuel Cycle Technologies program, under contract DE-AC05-00OR22725 with UT-Battelle, LLC. 


\section{References}

Benjamin B. Cipiti and Michael McDaniel. Reprocessing plant scale model integration. Sandial Report SAND2012-7779, Sandia National Laboratories, Albuquerque, New Mexico 87185, U.S.A., September 2011.

Benjamin B. Cipiti, Valmor F. de Almeida, Ian C. Gauld, Joseph F. Birdwell, and David W. DePaoli. Coupling a transient solvent extraction module with the separations and safeguards performance model. Sandial Report SAND2009-6307, Sandia National Laboratories, Albuquerque, New Mexico 87185, U.S.A., October 2009.

Valmor F. de Almeida. Progress on plant-level components for nuclear fuel recycling: Commonality. Letter Report ORNL/LTR-2011/176, Oak Ridge National Laboratory, Tennessee, TN 37831-6181, U.S.A., July 2011. Also available by request to dealmeidav@ornl.gov.

Valmor F. de Almeida. Plant-level modeling and simulation of used nuclear fuel dissolution. Technical Manuscript ORNL/TM-2012/375, Oak Ridge National Laboratory, Tennessee, TN 37831-6181, U.S.A., September 2012. Also available by request to dealmeidav@ornl.gov.

Benjamin E Lewis. An unsteady-state material balance model for a continuous rotary dissolver. Technical Manuscript ORNL/TM-9019, Oak Ridge National Laboratory, Tennessee, TN 37831-6181, U.S.A., October 1984.

Benjamin E Lewis and F. E. Weber. A mathematical model for liquid flow transients in a rotary dissolver. Technical Manuscript ORNL/TM-7490, Oak Ridge National Laboratory, Tennessee, TN 37831-6181, U.S.A., October 1980. 